DoI: http://dx.doi.org/10.11157/sites-vol11iss1id249

- ARTICLE -

\title{
[RE]IMAGINING SAME-SEX CIVIL UNIONS
}

\author{
Dionne Louise Steven
}

\begin{abstract}
In this paper I fashion an understanding of the relatively recent phenomenon of same-sex civil unions in Aotearoa/New Zealand. Drawing on fieldwork, I explore the contours of 30 couples' civil union ceremonies. I argue that civil unions as cultural performances can be defined as reflexive and biographical representations that for many couples were shaped by a historic dialectic based on exclusion. In constructing their ceremonies, couples, in varying degrees, drew on both queer and heteronormative meaning-constitutive practices but also felt free to introduce elements of a more innovative nature. The gravity of the occasion, the affective nature of ritual, and the socio-historical significance of same-sex civil unions combined to make most couples' civil union a highly emotional and meaningful experience. The transformative effects of 'ritual' were, however, by no means limited to the couple. Often the most profound outcome of couples' civil unions was the positive shifts that occurred with family of origin.
\end{abstract}

\section{INTRODUCTION}

The enactment of the Civil Union legislation in 2005 made it possible for the first time in New Zealand's history for same-sex couples to enter into a relationship that, from a legal perspective at least, was equivalent to marriage. The significance of the Civil Union Act 2004 in the history of gay rights is perhaps eclipsed only by the Homosexual Law Reform Act 1986, which brought to an end 128 years of criminalising male homosexual activities. In less than 20 years, New Zealand society shifted from defining homosexuals as criminal and 'unnatural' to a position whereby the state legally sanctioned their relationships.

In this paper I examine same-sex civil unions through the life narratives of 30 couples who chose to formalise their relationships. The paper is based on fieldwork conducted between 2008 and 2010 (thus prior to New Zealand's 
Marriage [Definition of Marriage] Amendment Act 2013, which allows samesex as well as opposite-sex couples to marry). The research explores why it was important for those couples to have a civil union, how they chose to mark or enact the occasion, and the meanings they attribute to their choices and actions. My focus in this paper is on couples' ceremonies: the different forms their ceremonies took in terms of scale, style and symbolic content; what social and cultural resources they drew upon in constructing their 'wedding ${ }^{1}$ and who it was important for couples to have present. I then examine the experiential aspects of couples' ceremonies and reveal how for many they were much more meaningful than they had anticipated.

My work is situated within a rich new vein of empirical explorations into the practices, meanings and effects of same-sex relationship recognition. The studies of Lewin (1998), Stiers (1999) and Hull (2006), for example, are based on the non-legal commitment ceremonies of same-sex couples in the United States. Mason, Shipman and Smart $(2006,2007)$ conducted a similar study within a British context. More recent studies, such as those of Badgett (2009), Green (2010), and Lash (2012) are based on legal same-sex 'marriage'2 in the United States, Netherlands and Canada. In New Zealand, empirical research on same-sex civil unions has, until recently, been noticeably absent. Baker and Elizabeth's (2012) research explores how same-sex and different-sex couples negotiate the transition from cohabitation to 'marriage,' the perceived differences between marriage and civil unions, and the socio-political context surrounding civil unions. Despite the legality of civil unions, their study finds that civil unions are still perceived by many as 'second-class marriage' (Baker and Elizabeth 2012).

My research distinguishes itself from Baker and Elizabeth's study by focussing exclusively on same-sex civil unions and the experiences of couples that have already formalised their relationship. It also highlights the 'normalising' effects of same-sex civil unions and how gay men and lesbians have, as a consequence, experienced a greater sense of acceptance and inclusion both at a familial level and at the level of mainstream society. Like Lewin (1998), Stiers (1999), Hull (2006) and Green (2010), my research also draws attention to a recurring tension between assimilation and difference, resistance and conformity, and to the ways in which people in 'late' modern society simultaneously draw upon both 'traditional' and 'modern' scripts in creating their identities, lifestyles, and ways of relating. In analysing participants' ceremonies I also draw on ritual theory (as do Lewin [1998], Stiers [1999] and Lash [2012]), in particular the work of Victor Turner. Following Turner, my analysis emphasises the processual nature of rituals by locating participants' ceremonies and the meanings they 
attach to their choices and actions within broader historical processes of both a personal and socio-political nature. In doing so I provide a more contextual understanding of these events and how they fit within participants' overall biographical narratives.

In-depth joint interviews with 12 male couples and 18 female couples form the basis of my study. All couples had entered into a same-sex civil union or, in the case of one couple who emigrated from Britain, a registered civil partnership (the British equivalent of a civil union). Couples' relationships ranged from three to 45 years in duration and participants' ages from 27 years to 80 years. Couples were recruited via mutual acquaintances, word of mouth, an email list for lesbians living in the greater Wellington region, progressive community Christian groups, and various other lesbian, gay, bisexual and transgender (LGBT) groups throughout New Zealand. The majority of couples were located in the urban centres of Auckland, Wellington and Christchurch. I also interviewed couples living in provincial parts of New Zealand. Most people I interviewed identified as Pākehā or as of European descent. Four women identified as Māori, one as a New Zealand-born Samoan, and one male participant as Indo-Zimbabwean. All but two interviews took place in the couples' home, a setting that was both convenient and comfortable for participants but also allowed me to observe the environment where their relationships were largely lived out.

Turner's notion of 'cultural performance' has efficacy as a framing concept for couples' civil union ceremonies and, in part, accounts for their highly varied nature. Cultural performances are those concerned with representation. They are a form of reading of experience, a story that people tell themselves about themselves (Geertz 1993, 448). Ritual is a particular genre of cultural performance. Although its formal characteristics are transferable to other genres of performance, ritual can be distinguished 'in the area of meaning and effect' (Moore and Myerhoff 1977, 8). As Turner explains, rituals are 'transformative performances' involving symbolic manipulation and references to religious beliefs (Turner 1986, 75; Deflem 1991, 6, 22). Even in modern secular societies, where the domain of religion has contracted, becoming a matter of individual choice, rituals are oriented ideologically towards 'matters of ultimate concern' (Turner 1977, 36; Turner 1976 quoted in Deflem 1991, 16). All civil unions are symbolic in that they represent a transformation in social status - to that of a legally recognised relationship. Some couples' performances, however, were more ideologically orientated than others and more elaborately incorporated symbolic elements of both personal and cultural significance, so in these respects can be described as more 'ritual-like' than others (Alexander 2006, 76). 
Constructing a cultural performance involves processes of imagination and reflexivity similar to those involved in the construction of self-narratives. People have to reflect back upon themselves and select those aspects perceived as important. A 'wedding', as cultural performance, can, therefore, be defined as a reflexive biographical representation, a resource for the display of self and the dyad relationship. Because my participants had already celebrated their civil union they were narrating their experiences retrospectively. My research then is based on a double imagining: first in terms of what participants imagined for their civil unions and, secondly, in terms of narrative imagining. For my part as the researcher, imagining was also required. While most participants shared with me photos of their civil union, listening to narratives and the particular words participants chose was the primary means for evoking an image of their worlds and their civil unions.

Contemporary ideas of 'individuality' and processes of 'detraditionalization' add a further layer of complexity to the reflexive construction of a 'wedding.' The notion that each of us has an original way of being human has fostered the idea that each couple's 'wedding' (straight or gay) should be an authentic expression of their own unique identity or lifestyle. The burgeoning wedding industry is no doubt partly a response to this ideal; the aim of the industry being to assist couples in crafting their very own, personalised wedding experience. Regulative traditions around marriage have also declined. Central to these changes is the relative decline in power inequality between the sexes or what 'late' modernity theorists (see for example, Bauman [2000], Beck and Beck-Gernsheim [1995], Castells [1997], and Giddens [1991; 1992]) refer to as processes of 'detraditionalization.' As 'moderns' we have more choice of options from which we make up our identities and lifestyles.

A distinguishing factor between same-sex and different-sex couples' weddings is their political context. While different-sex couples must negotiate between 'modern' and 'traditional' components in constructing their 'weddings,' same-sex couples have the added choice between heteronormative and queer meaning-constitutive 'scripts.' A negotiation between heteronormative and queer meaning-constitutive practices - expressed, more specifically, either as resisting or conforming to heteronormativity - was clearly articulated in participants' narratives of their civil union ceremony. Elements of 'innovation' were, however, also in ascendance. In examining the contours of participants' civil union ceremonies, I pay close attention to this tripartite tension. However these three factors were not discrete and often fused in creative ways to produce performances that reflected couples' particular lifestyle choices. 
A common concern for many couples during the planning stages of their civil union was how to negotiate proximity to, or distance from, a 'traditional' ${ }^{3}$ heterosexual wedding. Some participants wished to emphasise the comparability of their relationship to a heterosexual marriage, so consciously employed many of the 'traditional' customs associated with a heterosexual wedding in their own ceremony. Other participants, however, expressed a specific desire to distance themselves from a "traditional" or "straight"4 wedding.

This desire to distance their ceremonies from heterosexual weddings can be analysed on a political level and on a level of personal authenticity. Those participants who considered marriage and civil unions to be institutionally discrete were particularly mindful of not replicating a marriage ceremony. For those who considered the establishment of a separate institution as yet another example of gay discrimination, there was a political dimension to their choice of ceremony. As one participant expressed it:

I think part of why we did not copy a traditional marriage ceremony was because on one level it doesn't feel like it is a marriage. And it's like a political thing for me. It's not to pretend that it's the same because it's not equal. They are distinct categories as far as I'm concerned.

For other participants, their 'distancing desire' was motivated by a 'politics of difference.' The development of the modern notion of identity has, as Charles Taylor $(1994,38)$ observes, given rise to a politics which requires that society recognise the unique identity of an individual or group based on their distinctiveness from everyone else. In a politics of difference, assimilation into a dominant or majority identity is 'the cardinal sin and against the ideal of authenticity' (Taylor 1994, 38). A desire to distance themselves from a "straight" wedding is, in this context, evidence of asserting a unique identity and a corresponding act of resisting assimilation into mainstream heteronormative society. This stance was, no doubt, also informed both by their collective history as a stigmatized minority and the goals set down by the radical lesbian and gay liberation movements of the 1970 os and ' 80 : to affirm lesbian and gay identity and culture and to celebrate difference.

Typically accompanying these political motivations, however, was an overarching desire to create a ceremony imbued with authenticity and not one that might be perceived as a parody of a heterosexual wedding. One couple, who 
I shall refer to as Derek and Garth, ${ }^{5}$ were particularly emphatic on this point. They wanted their civil union to be as "un-wedding-like as possible." For them, this meant avoiding formality or anything that might be perceived as "high camp." In their words, "there was no walking down the aisle," "there were no buttonholes," "there were no speeches," "we dressed completely differently" and "we didn't have a cake." Derek said he had been to a commitment ceremony before civil unions were legislated in New Zealand where both males had their mothers give them away and had their sisters as "bridesmaids". Derek described this mimicking of a 'straight' wedding as "absolutely embarrassingly hideous" and something they particularly wanted to avoid in their own civil union: "We didn't want histrionics."

As a relatively new institution, civil unions have not yet developed their own language or body of customs. For those constructing a civil union this meant there were few precedents to draw upon. Having the freedom to create something completely original was for some couples a liberating prospect, while others described it as rather daunting. In the absence of any viable alternative, many couples found themselves drawn, albeit reluctantly, to the comparable and socially dominant wedding script. While modern notions of identity foster the idea that each couple's wedding should be an authentic expression of their own unique identity or lifestyle, this freedom is constrained by a need for familiarity. According to Bell, the absence of familiar 'ritual' components may compromise the authenticity of the performance: 'A ritual that evokes no connection with any tradition is apt to be found anomalous, inauthentic, or unsatisfying by most people' $(1997,145)$. The communicative effectiveness of a performance, indeed, largely depends, as Alexander notes, on 'an audience knowing already, without thinking about it, the categories within which actors behave' $(2006,58)$. Even performances of resistance 'depend on and redeploy dominant, hegemonic codes' (Alexander and Mast 2006, 15). According to Bell, though, this dance between 'tradition' and 'innovation' is a fundamental dimension of ritual and is especially necessary when a rite must be adapted to a new social context (1997 quoted in Lash 2012, 163).

Given the requirement for 'familiarity', it is not surprising that participants, in varying degrees, relied on an array of wedding-related references when constructing their ceremonies. Weddings provide the comparable templates for civil unions but also a pre-existing stockpile of symbols whose meanings are already explicit. Because of its widespread social intelligibility, the extended rituals of marriage become as Hull observes, 'the logical and interpretable way to signify commitment to an intimate partner in contemporary culture, so even those gay men and lesbians who are least invested in marriage as a cul- 
tural form sometimes find themselves drawn into marriage's cultural orbit' (Hull 2006, 198; original emphasis). Some participants found that the social dominance of the wedding script also created certain expectations among family and friends and a corresponding feeling of pressure to conform.

In constructing their performances, participants typically selected those wedding-related references that resonated but also felt free to 'invent' new ones of their own and to rearrange old symbols and give them a 'new' meaning. By far the most common 'traditional' symbol selected by participants for their civil union was rings. Rings symbolised their love and commitment to each other but also signalled to the outside world that they were attached or spoken for. For some participants there was also a political dimension to wearing a wedding ring as it provided an opportunity to make a statement. Other established wedding-related references drawn upon by couples included people giving readings, the cutting of a cake, family and friends making speeches, acknowledging 'absent friends,' and couples affirming their vows with a kiss. Of the extended rituals of marriage, some couples had either a "stag" or a "hens" night, and a few couples specifically planned to have a "honeymoon." Several couples reported receiving gifts from their guests but some said they had asked guests not to bother. Male participants generally dressed either in a suit or in a semicasual trouser and open-necked shirt ensemble. Most wore non-matching outfits but two male couples wore what can be described as coordinated outfits. None of my female participants wore white wedding-style dresses or, as one participant described them, "meringues." The majority did, however, choose to wear either a dress or a skirt for the occasion.

The use of wedding-related customs can on one level be seen as capitulating to heteronormativity, but on another can be interpreted as political in that it challenges the perceived heteronormativity of 'marriage', thereby forcing a redefinition. References to a queer 'tradition' also featured and were typically elaborated through the use of humour, iconic gay symbols, and references to the socio-historic significance of same-sex civil unions. The humour employed by participants often reflected a Camp 'sensibility.'While Camp is an aesthetic based on parody and exaggeration it is also a very serious analysis conducted by people who are willing to make fun of themselves to prove a point. In this way, Camp may also be a form of political resistance or oppositional critique expressed through irony. As Padva explains, 'Camp, as queer counterculture and counter-praxis, undermines and reconsiders the epistemology intended by the bourgeois to produce and reproduce, present and represent its hegemony. Camp not only subverts and revises the dominant ideology but also creates, produces, and performs counterculture' (2000, 237). 
Camp in both senses - parody and subversive irony - was a feature in several participants' civil unions. When people arrived at Heather and Jill's civil union, for example, they were greeted by a large poster that had an image of Heather and Jill's heads superimposed onto "meringue" wedding frocks. The poster was intended to strike a humorous note and was a link to their invitations, which were a spin-off of the locally well-known Tui beer advertising campaign. They read: "See Heather and Jill in matching meringue frocks" which was then followed by the Tui line: "Yeah, right." The multi-vocal nature of symbols, as Turner $(1986,24)$ notes, means that a symbol may subvert on one level what it simultaneously appears to be 'saying' on another. In this instance, the poster was on the one hand conveying the message that Heather and Jill were getting married and, on the other hand, it was parodying dominant heterosexual wedding practices i.e. the wearing of a white "meringue" wedding dress.

Several participants' civil union performances incorporated iconic gay symbols such as the rainbow flag. The rainbow flag has been used as a symbol of lesbian, gay, bisexual and transgender (LGBT) pride since the 1970s; the array of colours in the rainbow representing the diversity of the LGBT community. Will and Geoffrey made their "grand entrance" down a "sweeping staircase" accompanied by the iconic drag queen song, I am what I am, sung by another gay icon, Shirley Bassey. The "huge fireplace," which was the backdrop to their ceremony, was decorated with rainbow flags and flowers. Everyone who attended Evan and Bill's wedding was given a "blow wave bag" containing a rainbow flag, a balloon, a piece of string and a note which read: "blow up the balloon, tie on string, wave the flag and parade with pride." Celebrants typically acknowledged, in their speeches, the socio-historical significance of same-sex civil unions and how, until homosexual law reform, gay men had been classified as criminals.

\section{GUEST LIST NARRATIVES}

In discussing how a same-sex wedding impacts upon close personal relationships, Carol Smart argues that the ceremony is ' "fateful moment" at which point lesbians and gay men must necessarily take stock of relationships which are meaningful to them' $(2007,671)$. For many of my participants, 'coming out' as a gay man or lesbian had a destabilising effect on their familial relationships, particularly those with parents. For some, this period of disjunction was relatively short-lived while for others it was ongoing or even permanent. For most participants, though, having family and friends attend their civil union was described as extremely important. For participants who had experienced familial acceptance relatively early on, this wish was typically expressed as a desire to celebrate their relationship and commitment with those people most 
meaningful to them. For others, an important motivating factor in having a civil union was a desire to gain recognition, acceptance and support, primarily from family of origin. These participants often used their civil union as an opportunity to express to others what their relationship means and how it should be treated. By having a civil union they hoped to demonstrate the strength and depth of their commitment to each other and to assert the relative equality of their relationship to a heterosexual marriage.

The legitimacy conferred through legal recognition also often translated into a greater sense of entitlement in terms of sharing their relationship and commitment with a broad mix of social networks. For many participants it was the first time they had brought together the different parts of their lives. Whilst it is not unusual for people to have different 'clusters' of social relationships, gay men and lesbians are perhaps more inclined to keep different groups of people "compartmentalised," particularly if they have been 'closeted' about their sexuality, experienced episodes of homophobia, or had issues with family accepting their 'orientation.' Those couples who had performed commitment ceremonies or ceremonies to mark relationship milestones prior to the civil union legislation often said they felt entitled, or, in some instances, even duty-bound to have a bigger ceremony for their civil union and to include previously excluded 'straight' relatives. Beth, for example, commented that their tenth anniversary celebration had been a relatively private and "safe" affair. Their civil union, by comparison, was far more public: "I felt absolutely entitled to invite [her partner's] family and the next generation of my family and a wider range of people to this. Yeah, it was very much about standing up in front of the broad mix of our community."

Guests' attendance at the civil union was highly valued by couples and many went to extraordinary lengths to include family and friends and to style a ceremony and party that would bring everyone together. Bringing together family and friends, if only for a day, was often described by participants as one of the most significant aspects of their civil union and considerable satisfaction was voiced by those whose family had attended and provided visible support - perhaps most remarked, as Smart notes, 'because it could not necessarily or automatically be relied upon' $(2007,683)$. Several participants did, however, invite family of origin members who, for various reasons, chose not to attend. While the rejection implied by their absence was acknowledged, it generally was not framed as a major source of disappointment, rather as something almost expected. Other couples, by comparison, sent invitations to people "just for polite reasons" and were surprised when people living overseas accepted. This response often made the couple feel duty-bound to then organise an event 
worthy of the effort guests were making on their behalf.

\section{NARRATIVES OF LIFESTYLE REPRESENTATIONS}

Most participants described wanting their civil union to be a personal affair that reflected who they are as a couple and as individuals. For some this meant a low key or private ceremony, while for others it meant a highly public affair. Many participants enacted their civil union ceremony at places and at times that were of personal significance. Several couples chose the anniversary of their meeting or the same date as an earlier commitment ceremony. Having the same date as another anniversary acknowledged the commitment they had made to each other in the absence of any formal recognition of gay and lesbian relationships. In more pragmatic terms, it also helped, as some participants noted, to limit the number of anniversaries to be remembered and celebrated.

Two couples chose to hold the official part of their civil union in a registry office. Most other couples, however, chose a location that expressed a particular aspect of their lifestyle. Spaces that were meaningful in participants' everyday - non-ritualised - world were sometimes selected as the venue for their ceremony. For some, this was their home. For others, it was a park they "loved" and where they regularly exercised their dogs. Yvonne and Loana selected a marae as the location for their civil union ceremony because of its cultural resonance. Other participants chose their venue on the basis that it was an expression of their "local" identity.

A few couples chose to write their entire ceremony themselves but most reported that their celebrant had provided them with different wording options from which they selected parts they liked and added personalised phrases and sentiments. The focal point of a ceremony is when the couple make their statements of commitment to each other or their "vows." The sentiments conveyed in the wording of the statements some participants shared with me largely referred to the nature of love and their commitment to share a life together. Some "vows" also alluded to values and aspirations and their joint pledge to foster these in each other and in their relationship. Some couples recited the same vows to each other, whilst others said different things. One couple said they had wanted to listen to what they were committing themselves to rather than worrying about getting "the words out right." They had their celebrant recite their vows for them, which they then affirmed by simply saying, "I do."

In her study of same-sex 'weddings' in the United Kingdom, Smart (2008) focuses on the decisions taken by couples on the style of their wedding. More 
specifically, she examines what the final choices meant in terms of how couples negotiated the personal and the political and how they wanted to present themselves to the wider world (Smart 2008, 765). The negotiated choice of ceremony, she argues, is linked to a couple's style of political engagement (Smart 2008, 763). Using the notion of 'personal-political style,' Smart elicits four forms or styles of wedding from her research data: 'regular' weddings, 'minimalist' weddings, 'religious' weddings and 'demonstrative' weddings (2008, 765). In distinguishing between these four forms, Smart 'seeks to show how the mixture of personal and political can take different shapes while still conveying significant meanings' $(2008,765)$. 'Minimalist' weddings were private affairs while 'demonstrative' weddings were defined by their very public nature. 'Regular' weddings were located variously in-between and 'religious' weddings were those where a religious or spiritual component was described as mandatory.

The four forms of 'wedding' identified by Smart offer a useful heuristic tool for examining my own participants' styles of 'wedding.' Whilst Smart linked the forms specifically to a couple's style of political engagement, I use them to frame the parameters of my participants' civil union ceremonies more generally in terms of a private-public continuum. Moreover, rather than use the labels prescribed by Smart I defer to the descriptive language employed by my participants. I refer to the four forms of 'wedding' as 'full-on and fabulous,' 'personal and relaxed,' 'private and no-fuss' and 'spiritual.'

Seventeen couples had ceremonies that could be classified as 'personal and relaxed.' These 'weddings' were the most diverse category in terms of cost (from a few hundred dollars up to $\$ 40,000$ ), size and location. The congregation for these weddings was generally made up of a mixture of family and friends ranging in number from 15 to 80 . They were held in a secular environment and were followed by a modest reception or party. Half were held in private homes while the rest were held in public venues, outdoor spaces, commercial venues, and so on. 'Home-based' civil unions tended to be fairly relaxed and inclusive in style. A desire for informality is quintessentially 'kiwi' and reflects an ethic of egalitarianism. For many participants it was also important that their guests feel comfortable. Having a relaxed and inclusive style 'wedding' was more likely to facilitate an atmosphere of ease and encourage intermingling between the couple's different social groups. 'Public venue' civil unions were not necessarily any more formal than 'home-based' civil unions but generally involved a greater financial investment due in part to venue hire and/or catering costs.

Four female couples described having a religious or spiritual component to their civil union as extremely important. Three of these couples chose to have 
the formal part of their ceremony in a church. Rather than a simple capitulation to tradition, though, their choice reflected their ideology and lifestyle. A desire for a spiritual component did not also automatically suggest a conventional type of ceremony either. Part of Trisha and Pam's motive for wanting a church wedding was so their family would see their relationship as comparable to a heterosexual marriage. Trisha is also a minister in the Methodist Church. A friend, who is a Methodist minister and a lesbian, was their celebrant. As part of her sermon, she referred to the political significance of Trisha and Pam's actions.

Four couples had 'weddings' that can be described as 'private and no fuss.' For these participants, publicly asserting their commitment to outsiders was not of paramount importance. They instead chose to enact the official part of their civil union in a private, even discrete fashion. Rather than being devoid of any kind of social or political statement, though, Smart suggests that a 'rejection of the social display element of weddings may be the most politically radical of all, precisely because it can evade those constraining expectations' $(2008,768)$. A political act of non-conformity was part of Brad and Marcus's motivation for having a private wedding. Expense was also a consideration. The official part of their 'wedding' was conducted in the presence of the requisite two witnesses at their celebrant's house. Prior to leaving for their celebrant's house, though, they had what they referred to as their own private "ritual" at home in front of the shrine they had created for "symbolic objects." After their private "ritual," Brad and Marcus met with their witnesses, two close male friends, and went to the celebrant's house where the official part of their civil union was conducted. At the conclusion of the formalities, the five of them had a drink together, took some photos, and then Brad and Marcus went out for dinner with their two witnesses.

Whilst 'private and no fuss' weddings had both personal and political objections to public display, the opposite could be said for those who chose a 'fullon and fabulous' wedding. The five couples who chose this style of 'wedding' generally wanted to make their personal commitment as public as possible and, in many cases, this public aspect was also tied to their sexual politics. The important feature for these couples was 'that their wedding could not be overlooked' (Smart 2008, 771). When I asked Yvonne to recall what she had envisioned for their civil union, she replied:

I wanted a thing that says, yes, we are getting married and we are having a very big party to celebrate that. And we are not having 
some little ceremony, a quiet thing, to acknowledge our relationship. It's like, no, this is a real wedding. [...] It's like, we are not going to do this little [i.e. on a small scale]. If we are doing this we are doing this big and we are doing this flash and we are putting some serious money into this [...] We wanted people to walk into it and go, 'wow, this is amazing!'

The number of guests in attendance at 'full-on and fabulous' weddings ranged from 80 to 250 . Most 'full-on and fabulous' weddings involved a great deal of planning and attention to detail, becoming something of a major production.

The more innovative dimensions of couples' ceremonies were often the most reflexive and 'ritual-like' actions and were the site where symbols of personal significance, ideology, and aspects of theatre intersected. Chris and Deanne ordered butterflies from an online retailer, to be released during their ceremony. Opening and releasing the butterflies created a dramatic and emotive focal point and for Deanne and Chris was the stand out moment of their ceremony. Butterflies have a special significance for Chris and Deanne. A few years earlier, Chris had made the decision to transition to male. Butterflies are the symbol for transgender, representing the metamorphosis a person must go through when transitioning.

Yvonne and Loana's wedding provides another vivid example. Yvonne is Māori and Loana a NZ-born Samoan. The formal part of their civil union was held on the Te Papa Marae. They entered the Marae to the sound of a karanga. ${ }^{6}$ Passing through the large opening doors created a dramatic entrance and, according to Yvonne, represented the symbolic parting of Rangi and Papa in Māori creation stories. A waiata ${ }^{7}$ was then performed by their takatāpui ${ }^{8}$ kapa haka ${ }^{9}$ group and Loana's "PE mates" performed a haka. Ancestors were acknowledged as were all lesbian and gay couples of the past that had not had the opportunity to "marry" or, to even live openly together as a couple. Samoan music of personal significance was then played while the register was signed. Rather than exchanging rings, they unwrapped their fingers to reveal tattooed rings. Their tattooed rings symbolised the significance of their commitment to each other in that it was "written in blood" and, therefore, "forever" but also provided an intersection with their Māori and Samoan cultures where tattooing is customary. Through the conscious manipulation of personally relevant symbols, culture, sexual identity, and whakapapa converged, creating a performance that was both evocative and engaging for their audience. 
Most participants experienced their civil union as a highly significant and meaningful occasion. Reflecting upon their civil union event, Yvonne commented:

It was incredible, an absolutely incredible day. I had to take back and apologise to the universe because I've watched things on TV and I've been, in the past, very cynical, you know, with brides saying it was the most important day, most beautiful day of their life. And, having put in the effort to organise it and making it all happen, it just so was. It's such a step up to actually decide to bring all the parts of your life together in a way that only happens if you get married or if you die. And when you get married you have to face it. And there's no other time when that really happens for you.

Some participants recalled feeling extremely nervous on the day, although only two participants framed this response in terms of having second thoughts. For most, their nerves were about being the centre of attention, publicly declaring very personal feelings and beliefs that had, until this point, been confined largely to the dyad relationship, and the gravity of what they were about to commit to. Lara also recalled that she had been "worried about how [her] family would be on the day with queer stuff; I didn't want them to be upset."

Several male participants who had been together for many years or who had justified having a civil union in quite pragmatic terms, expressed amazement at how emotional and meaningful they had found their civil union. Brad and Marcus were ambivalent about civil unions because in their view they perpetuated gay discrimination. A major motivating factor in their decision to have a civil union was that it gave them access to a legal framework. Brad was, therefore, surprised at the emotional impact their civil union had on him. "It's had a deep effect on me. That was the surprising thing. I talked about it quite a lot afterwards that emotionally it had an effect that I didn't expect it would.'

Will, similarly, did a complete " 360 degree turn" when it came to their civil union. "Having been very ho-hum [about a civil union], I ended up being very, very much affected by the whole thing." Reflecting on why he found their civil union so moving, Will (aged 65) commented:

It may be part of our growing up, marriage. It's something you become aware of when you're very young. It's what happens to other 
people and how it's a big social and important event within a family. And suddenly we were part of that whereas, because of our upbringing, being illegal and all that rhetoric, we've always been outside the mainstream. And I think the civil union suddenly makes you more included in society. And I think it could be something to do with that. And you can't get away from the importance of having all your nearest and dearest in the room witnessing something - a ceremony like this - and so I think that added much more weight to it as well. It's something I will treasure forever, a wonderful time.

The very act of congregating is an extremely powerful stimulant that may produce what Durkehim refers to as 'collective effervescence.' Collective effervescence, like Turner's notion of 'communitas', is usually experienced as a deep or intense emotion, which can also be transformative in nature (Olaveson 2001, 104). Symbols also have a sensory quality and an ability to arouse emotions. The liminal nature of rituals, furthermore, often makes them an acceptable outlet for the expression of emotions that might in ordinary circumstances be deemed inappropriate (Kertzer 1988, 99). The strong emotions associated with rituals of transition are, according to Kertzer, also often a reflection of 'the inner conflicts, uncertainties and fears that afflict people in such circumstances' $(1988,100)$.

While emotions are 'subjectively felt and interpreted,' they are also 'socially and symbolically produced, expressed, and felt' (Leavitt 1996, 531-532). The processes of socialisation and retrospective contemplation give feelings their meaning and, to some extent, is what produces them. One celebrant noted that many participants had "gone through a lot to get to this point where they are." 'Coming out' for many participants was a "traumatic experience" that in a few instances resulted in alienation from family members and exclusion from mainstream society more generally. For several participants, who had lived much of their adult life on the margins of society, there was a surreal element to the occasion. After years of society defining them as criminal and/or unnatural, the state was now legally recognising and sanctioning their relationships. A same-sex civil union ceremony, furthermore, ultimately embodies the sexuality of the couple, making it something to celebrate and share rather than something to hide. A civil union in this way moves beyond simply treating same-sex couples with equal dignity to respecting them as a same-sex couple. For many participants, their civil union represented inclusion into an important meaning-constitutive practice as well as incorporation into mainstream society. A civil union in this respect optimises the notion of a rite of passage in a dual sense: not only does it mark a transition in social status to a legally 
recognised relationship, it also signals greater recognition and incorporation for gay people as citizens.

Often the most profound outcome of a couple's civil union was the shifts that occurred in their relationships with family of origin. Many participants felt their civil union had helped to "normalise" their relationship and that this normalisation had helped to accelerate processes of familial acceptance and incorporation. For some friends and family, attending a same-sex civil union constituted a form of 'coming out.'Attendance suggested at least a degree of acceptance and, at best, an affirmation of the couple's relationship. As Hull notes, 'the act of deciding to have a public ritual [...] forces others to make what amounts to a political decision, because merely showing up constitutes active participation in the ritual' $(2006,72)$. For a few family members, attending the civil union even assumed the significance of a personal rite de passage involving what Gilbert Herdt (1987) might refer to as a process of 'radical resocialization.' According to some participants' accounts, previously homophobic relatives underwent a transformation, if not in status then in attitudes, becoming firm advocates for gay equality.

Law in a democratic society has powerful symbolic capacities and the ability to shift the boundaries of wider society in terms of what is deemed socially and culturally acceptable. For many participants' families, the legitimacy conferred through legal recognition played a significant role in re-framing their loved one's same-sex relationship as socially 'normal'. The legitimising effects of law also intersected with the socially dominant cultural model of marriage to invest the same-sex relationship with meaning beyond just sex. Importantly for family members, the widely understood framework of marriage also provided a code for locating the partner in kinship terms; this person is like a wife or a husband and, therefore, a son/daughter, sister/brother-in law. The effective and affective qualities of ritual, furthermore, worked to intensify the connection between ritual participants and the symbolic objects of communication and, in doing so, had the ability to transform the attitudes and behaviour of those present (Alexander 2006, 30; Deflem 1991, 5).

\section{CONCLUDING COMMENTS}

In this paper I have explored the contours of same-sex civil union ceremonies. How to negotiate proximity to and distance from a 'traditional' heterosexual wedding was a common concern for many participants in the planning stages of their civil union. Some wished to draw a parallel between what they were doing and a heterosexual marriage so consciously drew on 'traditional' wed- 
ding-related customs. Others, however, wished to distance themselves from a "traditional" or "straight" wedding. This distancing desire was, as I have discussed, informed both by a 'politics of difference' as well as a desire to create a ceremony imbued with authenticity and not one that might be interpreted as a parody of a heterosexual wedding. A need for familiarity, however, typically meant that participants selected those wedding-related references that resonated but also felt free to 'invent' new ones of their own or to rearrange old symbols and give them a 'new' meaning. The use of wedding-related customs can on one level be seen as a capitulation to heteronormativity, but on another can be interpreted as political in that it challenges the perceived heteronormativity of 'marriage', thereby forcing a redefinition. A queer 'sensibility' was evidenced through touches of humour, the use of iconic gay symbols, and references to the socio-historic significance of same-sex civil unions.

In tracing the shape of couples' ceremonies, I demonstrated how queer and heteronormative meaning-constitutive practices fused with more innovative elaborations to produce authentic performances reflective of the couple's particular lifestyle. The more innovative dimensions of couples' ceremonies were often the most reflexive and 'ritual-like' actions and were the site where symbols of personal significance, ideology, and aspects of theatre intersected. Most participants experienced their civil union ceremony as highly significant and emotional. For some male participants, in particular, this response was both unexpected and surprising. The emotions experienced by participants during their ceremony can, as I have argued, be attributed to the gravity of the occasion and the affective characteristics of ritual, but were also shaped by an historic dialectic based on exclusion. The transformative effects of ritual were, however, by no means limited to the couple. Often the most profound outcome of a couple's civil union was in fact the positive shifts that occurred in their relationships with family of origin.

\section{NOTES}

1 The word wedding when enclosed in single quotation marks ('wedding') refers generally to a ceremonial act of joining rather than specifically to the act of marrying.

2 The word marriage when enclosed in single quotation marks ('marriage') refers generally to all forms of legal recognition for same-sex couples e.g., marriage, civil unions, registered partnerships, life partnerships, and domestic partnerships. 
3 While I acknowledge that the term 'tradition' tends to oversimplify complexities, I use the term when specifically employed by participants in narrating their civil union experiences.

4 Words or terms appearing in double inverted commas denote those used by research participants.

5 All participants' names have been changed for ethical reasons.

6 A karanga is a Māori ritual chant of welcome.

7 A waiata is a Māori song.

8 The term 'takatāpui' was first recorded in 1834 in the Williams Dictionary of the Māori Language and was used to refer to 'an intimate companion of the same-sex' (Aspin 2005). In a contemporary context, the word takatāpui has been reclaimed and is used to refer to a person who is Māori and either gay, lesbian, bisexual, transgender, or transsexual. Takatāpui, like the term 'queer', is therefore gender neutral but also provides an intersection between sexual orientation and culture that other 'labels' do not and this was the reason given by Māori participants for using the term.

9 Kapa haka refers to Māori performing arts.

\section{REFERENCES}

Alexander, Jeffery. 2006. 'Cultural Pragmatics: Social Performance Between Ritual and Strategy' In Social Performance: Symbolic Action, Cultural Pragmatics, and Ritual, edited by Jeffery Alexander, Bernhard Giesen and Jason Mast, 29-90. Cambridge, UK; New York: Cambridge University Press.

Alexander, Jeffery, and Jason Mast. 2006. 'Introduction: Symbolic Action in Theory and Practice: The Cultural Pragmatics of Symbolic Action.' In Social Performance: Symbolic Action, Cultural Pragmatics, and Ritual, edited by Jeffery Alexander, Bernhard Giesen and Jason Mast, 1-28. Cambridge, UK; New York: Cambridge University Press.

Aspin, Clive. 2005. 'The Place of Takatāpui Identity within Māori Society: Reinterpreting Māori Sexuality within a Contemporary Context.' Paper presented at the Competing Diversities: Traditional Sexualities and Modern Western Sexual Identity Constructions Conference, Mexico City. 
Badgett, M. V. Lee. 2009. When Gay People Get Married: What Happens When Societies Legalize Same-Sex Marriage. New York: New York University Press.

Baker, Maureen and Vivienne Elizabeth. 2012. 'Second-Class Marriage? Civil Union in New Zealand. Journal of Comparative Family Studies 43 (5):633-645.

Bauman, Zygmunt. 200o. Liquid Modernity. Cambridge; Malden, Mass.: Polity Press; Blackwell.

Beck, Ulrich and Elisabeth Beck-Gernsheim. 1995. The Normal Chaos of Love. Translated by M. Ritter and J. Wiebel. Cambridge, UK: Polity Press.

Bell, Catherine. 1997. Ritual: Perspectives and Dimensions. New York: Oxford University Press.

Castells, Manuel. 1997. The Power of Identity. Cambridge, Mass: Blackwell.

Deflem, Mathieu. 1991. 'Ritual, Anti-Structure, and Religion: A Discussion of Victor Turner's Processual Symbolic Analysis. Journal for the Scientific Study of Religion 30 (1): 1-25.

Gauntlett, David. 2002. Media, Gender, and Identity: An Introduction. London; New York: Routledge.

Geertz, Clifford. 1993 [1973]. The Interpretation of Cultures: Selected Essays. London: Fontana.

Giddens, Anthony. 1991. Modernity and Self-Identity. Cambridge: Polity Press.

- 1992. The Transformation of Intimacy: Sexuality, Love and Eroticism in Modern Societies. Stanford, Calif.: Stanford University Press.

Green, Adam Isaiah. 2010. 'Queer Unions: Same-Sex Spouses Marrying Tradition and Innovation.' Canadian Journal of Sociology 35 (3):399-436.

Gross, Neil. 2005. 'The Detraditionalization of Intimacy Reconsidered.' Sociological Theory 23 (3): 286-311.

Herdt, Gilbert. 1987. The Sambia: Ritual and Gender in New Guinea. New York: Holt, Rinehart and Winston. 
Hull, Kathleen. 2006. Same-Sex Marriage: The Cultural Politics of Love and Law. Cambridge, UK; New York: Cambridge University Press.

Kertzer, David. 1988. Ritual, Politics, and Power. New Haven: Yale University Press.

Lash, Shari Rochelle. 2012. 'Jewish Same-Sex Weddings in Canada: Rites of Resistance or Rituals of Conformity?' In Negotiating Rites, edited by Ute Hüsken and Frank Neubert, 161-175. New York: Oxford University Press.

Leavitt, John. 1996. 'Meaning and Feeling in the Anthropology of Emotions.' American Ethnologist 23 (3):514-539.

Lewin, Ellen. 1998. Recognizing Ourselves: Ceremonies of Lesbian and Gay Commitment. New York: Columbia University Press.

Mason, Jennifer, Beccy Shipman, and Carol Smart. 2006. Gay and Lesbian 'Marriage': An Exploration of the Meanings and Significance of Legitimating SameSex Relationships. Manchester: Morgan Centre for the Study of Relationships and Personal Life, The University of Manchester.

Moore, Sally and Barbara Myerhoff. 1977. Secular Ritual. Assen: Van Gorcum.

Myerhoff, Barbara. 1980. Number Our Days. New York: Simon and Schuster.

Olaveson, Tim. 2001. 'Collective Effervescence and Communitas: Processual Models of Ritual and Society in Emile Durkheim and Victor Turner.' Dialectical Anthropology 26 (2): 89-124.

Padva, Gilad. 200o. 'Priscilla Fights Back: The Politicization of Camp Subculture.' Journal of Communication Inquiry 24 (2):216-243.

Smart, Carol. 2007. 'Same Sex Couples and Marriage: Negotiating Relational Landscapes with Families and Friends.' The Sociological Review 55 (4):671-686.

—. 2008 "Can I be bridesmaid?" Combining the personal and political in samesex weddings.' Sexualities 11 (6):761-776.

Steven, Dionne. 2013. 'Narratives of Incorporation: An Anthropological Analysis of Same-Sex Civil Unions in New Zealand.' Unpublished Doctoral dissertation, Wellington: Victoria University of Wellington. http://hdl.handle. net/10063/2765 
Article $\cdot$ Steven

Stiers, Gretchen. 1999. From This Day Forward: Commitment, Marriage, and Family in Lesbian and Gay Relationships. New York: St. Martin's Press.

Taylor, Charles. 1994. 'The politics of recognition.' In Multiculturalism: Examining the Politics of Recognition, edited by Amy Gutmann, 25-73. Princeton, N.J.: Princeton University Press.

Turner, Victor. 1977. 'Variations on a Theme of Liminality.' In Secular Ritual, edited by Sally Moore and Barbara Myerhoff, 36-52. Assen: Van Gorcum.

- 1986. The Anthropology of Performance. New York: PAJ Publications. 